INTERNATIONAL

FOOD POLICY

RESEARCH

INSTITUTE

IFPRI

IFPRI Discussion Paper 01335

March 2014

\title{
Agricultural Policy Processes and the Youth in Malawi
}

Mariam A. T. J. Mapila

Development Strategy and Governance Division 


\section{INTERNATIONAL FOOD POLICY RESEARCH INSTITUTE}

The International Food Policy Research Institute (IFPRI), established in 1975, provides evidence-based policy solutions to sustainably end hunger and malnutrition and reduce poverty. The Institute conducts research, communicates results, optimizes partnerships, and builds capacity to ensure sustainable food production, promote healthy food systems, improve markets and trade, transform agriculture, build resilience, and strengthen institutions and governance. Gender is considered in all of the Institute's work. IFPRI collaborates with partners around the world, including development implementers, public institutions, the private sector, and farmers' organizations, to ensure that local, national, regional, and global food policies are based on evidence.

\section{AUTHOR}

Mariam A.T.J. Mapila (m.mapila@cgiar.org) is an associate research fellow in the Development Strategy and Governance Division of the International Food Policy Research Institute, Washington, DC.

Notices

IFPRI Discussion Papers contain preliminary material and research results. They have been peer reviewed but have not been subject to a formal external review via IFPRI's Publications Review Committee. They are circulated in order to stimulate discussion and critical comment; any opinions expressed are those of the author(s) and do not necessarily reflect the policies or opinions of IFPRI.

Copyright 2014 International Food Policy Research Institute. All rights reserved. Sections of this material may be reproduced for personal and not-for-profit use without the express written permission of but with acknowledgment to IFPRI. To reproduce the material contained herein for profit or commercial use requires express written permission. To obtain permission, contact the Communications Division at ifpri-copyright@cgiar.org. 


\section{Contents}

Abstract $\quad$ V

Acknowledgments $\quad$ vi

1. Introduction 1

2. Definition of Key Terms and Concepts 3

3. Three Stage Model of Participation in Policymaking Processes 5

4. Analytical Framework $\quad 6$

5. Results and Discussions 9

6. Conclusions and Policy Recommendations 21

Appendix: Supplementary Tables 22

$\begin{array}{ll}\text { References } & 23\end{array}$ 


\section{Tables}

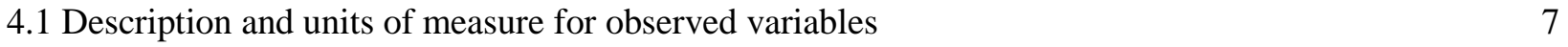

5.1 Results of principal factor analysis $\quad 10$

5.2 Pairwise comparison of communities by factors extracted 12

5.3 Major policies and strategies of the Malawi Ministry of Agriculture and Food Security: Youthspecific statements

5.4 Ego network measures for the sampled agricultural youth network in Malawi 17

$5.5 \mathrm{Key}$ informant solutions to overcoming networking hurdles for youth in agriculture 20

A.1 Principal axis factor analysis: Total variance explained 22

A.2 Spearman's rho results: Correlations between extracted factors 22

\section{Figures}

3.1 Forms or phases of the policy engagement process 5

5.1 Scree plot of factors determining youth engagement in community policy processes 9

5.2 Social network analysis: Malawi youth agriculture network 19 


\begin{abstract}
Evidence exists which shows growing disillusionment with and disinterest in agricultural-based livelihoods among the youth in Africa south of the Sahara. This disillusionment raises concerns for the future of agriculture for the developing world as it can lead to higher rural urban migration, unemployment and lowered agricultural productivity. The engagement of youth in agricultural policy formulation processes is seen as one avenue for motivating youth engagement in agriculture. This research seeks to develop a contextual understanding of the level of engagement of youth in agriculture thus providing evidence which can be used to stimulate youth involvement in the sector. Using a mixedmethods approach, this study analyzes the determinants of the engagement by southern African youth in agricultural policy processes using Malawi as a case study. Factor analytic results show that four interlinked latent factors determine youth engagement in agricultural policy processes: political patronage, availability of social amenities, access to information and educational services, and physical accessibility of the community. Results of a social network analysis demonstrate that government departments at the local level that are mandated to work on youth issues are the main hubs of information for youth in agriculture, with the Ministry of Agriculture playing a secondary role. Furthermore, the results show that youth in agriculture have little or no direct interactions with each other; and where interactions do exist, they are weak. Therefore, youth remain on the periphery of agricultural policymaking networks, and their role in shaping agricultural policy dialogues is negligible. This is attributable not only to lack of a deliberate government policy to include the youth but also lack of a unified youth platform. Conclusions are that in southern Africa the onus is on the youth to ensure that they are effectively engaged in agricultural policy dialogue. The creation of unified youth platforms for engaging with agricultural policymakers is essential for improving youth engagement in the policy process. Without such platforms, the voice of the youth on agricultural policy issues will remain barely audible among the cacophony of voices of other agricultural stakeholders.
\end{abstract}

Keywords: youth participation, factor analytic approach, policy process 


\section{ACKNOWLEDGMENTS}

This work was done with the help and oversight of Dolf te Lintelo of the Institute for Development Studies (IDS), University of Sussex, Brighton, UK; and Todd Benson of the International Food Policy Research Institute, (IFPRI), Addis Ababa, Ethiopia. Funding for this research was provided by the Futures Agricultures Consortium (FAC) as part of the early career fellowship. The author further acknowledges the insightful contributions of Cynthia Kazembe, Klaus Droppelmann, and John Mazunda. 


\section{INTRODUCTION}

In Africa south of the Sahara (SSA), people aged 30 years and under comprise 70 percent of the total population (Euromonitor 2012). In a ranking of countries with the youngest population, 6 of the top 10 countries are in SSA (Population Reference Bureau 2011. Many of the economies in the region are highly dependent on agricultural production, with approximately 65 percent of the total population in the region being employed in the sector. As such, some youth in SSA will pursue agricultural livelihoods in the short term so as to build capital with which to meet other social and economic needs, as well as to attain independence and then shift into other types of livelihoods (Okali and Sumberg 2012). Many others, however, will spend most of their lives in the agriculture sector (Proctor and Lucchesi 2012). A large body of emerging literature suggests a growing disillusionment with and disinterest in agricultural-based livelihoods among the youth (Bennell 2007; Leavy and Smith 2010; Anyidoho, Kayuni et al. 2012, cited by te Lintelo 2012; White 2012). The International Fund for Agricultural Development (IFAD 2011) attributes this to the lack of lucrative incentives in smallholder subsistence farming in many low-income countries. Sumberg (2012) notes that the agricultural sector is rapidly transforming with advances in technology and a trend toward globalized food systems. Although many opportunities are arising from this, rural youth often lack the necessary skills and resources with which to take advantage of the emerging opportunities.

The disillusionment of rural youth with agricultural livelihoods raises concerns for the future of agriculture for the developing world because it can lead to higher rural-urban migration, increased urban unemployment, and an insufficient number of experienced and motivated future farmers. As such, any strategies to revitalize and expand the agricultural sector in SSA requires that youth find sufficient incentives to facilitate their engagement and active involvement in the sector (Leavy and Smith 2010). Currently, many agricultural policies in Africa are not responsive to the needs of young farmers and investment in the development of youth opportunities within the sector is generally low (Proctor and Lucchesi 2012). Two reasons for this are (1) in many developing countries, youth are not given priority in policymaking, not only in agriculture but in all areas (Bennell 2007:5); and (2) lack of engagement of the youth in policy formulation processes. Increased engagement of the youth in such processes and youthfriendly agricultural policies could incentivize the youth to remain in the agriculture sector. A youthfriendly agricultural policy is one that would be developed with active engagement of the youth and that empowers and recognizes the youth as a differentiated group as a result of social, economic, and cultural differences. For an agricultural policy to be youth-friendly, it has to meet the needs of the youth. The needs of the African youth in agriculture include but are not limited to capital and finance, land with secure tenure, lucrative markets, and skills training in entrepreneurship and in farm business or agroenterprise.

The effective engagement of youth in priority setting and policy formulation processes is essential to designing truly forward-looking agricultural development policies and programs. First, doing so has the potential to foster the creation of youth-friendly policies in which the youth have a sense of ownership. Second, this will build the competence of the youth to publicly articulate their priorities and needs. The engagement of youth in agricultural policy formulation processes will nurture the creation of youth leaders in agriculture.

The research described in this report was undertaken in view of these emerging issues related to youth and agricultural development. This research seeks to develop a contextual understanding of the level of engagement of youth in agriculture. Using Malawi as a case study, the specific aims are (1) to analyze the barriers and enabling factors that determine youth engagement in agricultural policy processes from both the supply and the demand side, and (2) to assess the nature of networking and other interactions between youth and agricultural policymakers. In addition, the study aims to provide policy recommendations to improve youth engagement and to enhance youth participation in agricultural policy processes. 
Malawi provides an interesting case study because the youth form a large proportion of the country's population: more than half of the population (54 percent) is under the age of 18 years (Chinsinga and Chasukwa 2012). Secondly, the government explicitly recognizes empowerment of the youth as essential for achieving sustainable agricultural development. This is articulated in the Agricultural Sector-Wide Approach (ASWAp), a strategic development and investment plan for Malawi's agricultural sector, which provides for monitoring and evaluating the participation of the youth in decisionmaking, policy formulation, and implementation processes within the sector (MOAFS 2011). Insights from this research can be used to increase policymakers' knowledge of the issues affecting the youth in agriculture in the country. Greater understanding of youth issues in agriculture can go far in ensuring the development of youth-responsive agricultural policies. Such policies are needed to revive the popularity of farming among youth in southern Africa and to create greater opportunities for youth in the sector. Other essential factors needed to revive the popularity of farming among the youth include but are not limited to access to ownership of productive land mediated by social structures of inheritance, as well as access to credit and financial services.

The rest of this paper is organized as follows: Definitions of key terms and concepts used in the report are found in Section 2. Next, Section 3 presents a review of the literature pertaining to the importance of youth engagement in agricultural policy processes. Section 4 discusses the analytical framework of the study, with results and discussion in Section 5. The report concludes in Section 6 with summary, key conclusions from the study, and policy recommendations. 


\section{DEFINITION OF KEY TERMS AND CONCEPTS}

This section provides brief definitions of the key terms and concepts used in the paper.

\section{Youth}

The definition is culturally dependent and differs due to the purpose, such as legal versus policy issues. The Malawi National Youth Policy defines youth as all young females and males between the ages of 14 and 25 years (Malawi, MYSPC n.d.). The age range, however, is flexible depending on the context, and sometimes in Malawi it extends to include individuals up to 35 years of age (CASE n.d.). For the purpose of this study, we adopt the definition of people between the ages of 15 and 35 years. This study will include issues pertaining to youth engagement in agricultural policy processes for a cross-section of youth as follows:

- Category 1: rural youth that are currently engaged in farming or agricultural-based livelihoods

- Category 2: rural youth that are currently not engaged in farming or agricultural-based livelihoods 1

\section{Youth Organization}

A youth organization in the context of this study is a developmental-oriented group that exists to promote the economic and social empowerment of the youth. Therefore, an agricultural youth organization is one that exists to foster the ability of youth to better engage in the agricultural sector, in agricultural production, and in some specific cases perhaps also in agricultural policy processes.

\section{Policy}

The definition is nuanced, as it can be a set of decisions, the accompanying statements as captured in policy documents, or a course of action. Ideally, a policy should be consistent in all three (decisions, documents or statements, and actions). This study adopts the working definition of policy adapted from Sandford (1985) and Hayes (2009): a policy articulates the development priorities of government or society. A public policy is, therefore, a course of action taken in response to an identified problem. The course of action is often a specific government-financed process that adopts, implements, and enforces endorsed decisions.

\section{Agricultural Policy Process}

A policy process is the conceptualization, implementation, and evaluation of changes in policies (Dubois and Ciamarra 2009). The policy process involves different stakeholders within a particular context. An agricultural policy process is therefore the engagement of different stakeholders to develop new or revise existing agricultural policies.

\footnotetext{
${ }^{1}$ The key underlying assumption is that most rural youth in Malawi have access to small pieces of customary, family-owned land. As such, those youth not engaged in farming might be unmotivated (there may be other reasons, such as conflict with siblings claiming the land) by the prospects of being career subsistence farmers. This, therefore, leaves them either unemployed or underemployed either on-farm or off-farm as part-time or seasonal wage earners. Rural youth fully employed in the agricultural sector as either full-time farmers or full-time wage earners fall into Category 1.

This study excludes urban youth for two main reasons: First, the study assumes that urban youth not engaged in farming have other options for wage employment. Therefore, their lack of engagement in the agricultural sector is not necessarily a sign of disinterest with the sector. Second, urban youth that have a disinterest with the sector are difficult to identify due to the lack of a nationally representative dataset that captures information pertaining to youth aspirations - which can identify the youth.
} 


\section{Participation}

Defined as "the active, informed and voluntary involvement" (DFID 2010) of people in a development process. The forms of participation can vary. This study will focus on youth participation that enables the youth to work with or engage effectively with other stakeholders in Malawi in agricultural policy processes. This is opposed to the youth being merely consulted or having to simply legitimize decisions that are made by others. For participation to be empowering, the youth must be part of the development of the policy (through the consultation process) as well as be engaged in prioritizing activities, deciding how resources are allocated to policy priorities, and prioritizing objectives. In this study, youth participation is synonymous with youth engagement. 


\section{THREE STAGE MODEL OF PARTICIPATION IN POLICYMAKING PROCESSES}

The conceptualization of youth engagement in agricultural policy processes differs among scholars. The theoretical framework that guides this study is from an Organization for Economic Cooperation and Development (OECD) three-stage model for measuring the nature and extent of citizen participation in policymaking processes (OECD 2001; Curtain 2001). According to this model, engagement of youth in a policy process can take three forms: information, consulting, or partnership.

- The information form is a one-way process whereby government provides information to the youth. This is information related to policy processes that are taking place, as well as to issues on the policy agenda. In this form, the youth are "passive" recipients of information, and the government is active in disseminating information (Curtain 2001; OECD 2001).

- The consultation form involves the government consulting youth in the policy process. In this form, youth provide feedback on policy issues that have been predetermined by government. This two-way process creates an opportunity for feedback from the youth.

- The partnership form is where government ensures that youth are involved in proposing policy issues and are part of the policy dialogue. In this form, the youth are "partners" in that they are actively involved in policymaking but with government making the final decision (Curtain 2001).

Although the three forms of engagement can exist separately, they can also be considered as stages through which a policymaking process evolves (Figure 3.1).

Figure 3.1 Forms or phases of the policy engagement process



Source: Adapted from OECD (2001).

The policymaking process stages are not mutually exclusive, because information is a basic precondition and consultation is a central strategy in all policymaking processes (OECD 2001). In the partnership form, however, youth are involved from the onset and are aware of information shared and of how the consultation process is to proceed. They are required to contribute actively at each stage. 


\section{ANALYTICAL FRAMEWORK}

The study employs a mixed-methods approach to determine youth engagement in agricultural policy processes in Malawi. The study used both primary and secondary data. The primary data collected focused on key informant perspectives on the factors hindering youth engagement in agricultural policy processes, as well as on the level and depth of interactions between youth advocates and policymakers. The primary data were collected using key informant checklists and a semistructured, limited-choice questionnaire.

The study uses secondary data on the community-level involvement of youth in policy processes from the nationally representative 2010/2011 Integrated Household Survey (IHS-3) data for Malawi. Principal axis factoring was used to unearth the unobservable (underlying) factors determining youth engagement in community-level policy processes, and social network analysis was used to determine the depth and direction of interactions between youth advocates and policymakers at the national level.

Results from the principal axis factoring will provide a generic picture of the underlying factors affecting youth participation in community-level decisionmaking processes throughout the country. Insights from the social network analysis, on the other hand, will assist in understanding the key bottlenecks preventing the effective engagement of youth advocates working to influence agriculture policy at the national level. The social network analysis focuses on assessing youth advocates that are actively working to represent all youth in national-level agricultural policy forums. Understanding both the general factors affecting youth engagement in community-level policy processes and the specific bottlenecks faced by youth advocates is essential for developing effective strategies that will enable the youth in Malawi to engage in agricultural policy processes, be it at the community, local government, or national level.

\section{Principal Axis Factoring}

The underlying factors that affect youth participation in policy processes at the community level are unearthed using principal axis factoring. The study focused on community-level participation of youth in decisionmaking circles because policy dialogue in Malawi is driven at the local level. In the local government setup, the country has 28 local district assemblies (governments), which have autonomy in decisionmaking and resource allocation (the central government channels all developmental funds through local district assemblies). District assembly structures comprise government officials from different ministries (such as agriculture, health), traditional authorities, development agencies, and community representatives. Community representatives embody the views of different village development committees in which members of the community such as women, men, chiefs, and the youth can be part. This is one of the tangible community structures through which the views of individual community members filter through to the local government level, which then feeds to the national level. Principal axis factoring therefore unearths the underlying (latent) factors that determine youth inclusion in these community-level committees and policy forums.

Underlying factors are not directly observable or measurable by a single factor. In practice, one observes a range of variables that, in essence, are a reflection of fewer key underlying factors. Algebraically the common factor model is as follows:

$$
\begin{gathered}
X_{i}=a_{i 1} F_{1}+a_{i 2} F_{2}+\cdots \cdot a_{i m} F_{m}+e_{i} \\
X_{p}=a_{p 1} F_{1}+a_{p 2} F_{2}+\cdots \cdot a_{p m} F_{m}+e_{i},
\end{gathered}
$$


where: $\quad X \quad$ Variables - observed variables (ranging from $i$ to $p$ )

$F \quad$ Factors - latent underlying factors (ranging from 1 to $m$ )

$m \quad$ The number of latent underlying factors

$p \quad$ The number of observed variables

$a_{i} \quad$ Factor loadings or scores for variable $i$, and

$e_{i} \quad$ The part of the observed variable that is unexplained by the extracted factors

Factor analysis in this study included 24 observed variables. Table 4.1 provides the description and the units of measurement for all the observed variables.

Table 4.1 Description and units of measure for observed variables

\begin{tabular}{|c|c|}
\hline Variable & Description and unit of measure \\
\hline acc road & Tvpe of road in communitv $(1=$ tarmac/asphalt, $2=$ araded/aravel, $3=$ well-maintained dirt, $4=$ dirt $)$ \\
\hline acc_veh & Vehicles pass through community all year round $(1=$ yes, $0=$ no $)$ \\
\hline acc mbus & Number of months in last 12 months that main road was passable by a minibus \\
\hline acc lorry & Number of months in last 12 months that main road was passable by a lorry/truck \\
\hline acc_transp & Public transport (minibus, bus, regular informal taxi (matola)) stops in community $(1=$ yes, 0 \\
\hline dst bus & Distance in $\mathrm{km}$ to nearest bus stage \\
\hline loc_boma & Community is in district center (boma) $(1=$ yes, $0=$ no $)$ \\
\hline MK_boma & Cost in Malawian kwacha (MK) to reach district center (boma) \\
\hline Loc urban & Community is in major urban center $(1=$ yes, $0=$ no $)$ \\
\hline dst_mrk & Distance to nearest market in $\mathrm{km}$ \\
\hline dst_wmrk & Distance to large weekly market in $\mathrm{km}$ \\
\hline dst admarc & Distance to nearest ADMARC market in $\mathrm{km}$ \\
\hline dst_post & Distance to nearest post office in $\mathrm{km}$ \\
\hline dst_phone & Distance to nearest place with public fixed phone line in $\mathrm{km}$ \\
\hline edu Pteach & Number of teachers at nearest primary school \\
\hline Dst_sec & Distance to nearest public secondary school \\
\hline Edu CDSS & Number of teachers at nearest community day secondary school \\
\hline edu rsec & Number of religious secondary schools in community \\
\hline edu pvtp & Number of private primary schools in community \\
\hline Edu pvts & Number of private secondary schools in community \\
\hline dst cbank & Distance to nearest commercial bank \\
\hline dst mfi & Distance to nearest microfinance institution in $\mathrm{km}$ \\
\hline $\mathrm{mp}$ resident & Member of parliament resident in community $(1=$ yes, $2=$ no $)$ \\
\hline mp_visit & Member of parliament visited community in last 3 months to a hold a meeting \\
\hline
\end{tabular}

Source: Author's calculations.

Note: ADMARC is the Agricultural Marketing and Development Cooperation, a public marketing board responsible for selling and buying mainly food crops. It defends the announced government price of commodities.

This study uses principal axis factoring with varimax rotation. In principal axis factoring, the aim is to find the lowest number of factors that account for variability in the observed variables. Rotation finds factors that have easy interpretability and that are relevant to the analysis. Mathematically, rotation attempts to ensure that all variables have high loadings on only one factor (Tabachnick and Fidell 2000). Varimax rotation is the most widely used rotation algorithm in factor analytic approaches (Costello and Osborne 2005). This is because varimax rotation essentially ensures that each factor has a small number of large loadings and a large number of small loadings.

Factor scores extracted through principal axis factoring are incomparable to each other. However, different groups within the sample are comparable with each other by each factor extracted. Compare different types of communities with each other using the extracted factor scores. This comparison provides an insight into the factors affecting youth participation in community-level policy processes in 
different communities. The communities in the country were categorized into four groups based on the level of youth engagement in agricultural community-level processes.

As discussed earlier, rural communities have community-level committees that input into the district assembly decisionmaking forums. Therefore, this study uses youth engagement in those community-level policy processes as used as a proxy for youth engagement in agricultural policy processes. A Youth Engagement Index at Community level (YEIC) was developed using data from the community module of the IHS-3 data. The community module of the IHS-3 dataset captures communitylevel information such as access to basic services; economic activities; agriculture; changes occurring in the community; community needs, actions, and activities; communal resource management; and prices of goods and services in the community and surrounding area. In 2010/2011, a nationally representative sample of 768 communities across the country responded to the community module of the IHS-3. Each group consisted of 6-12 individuals per community. About 6,481 individuals across the country took part in responding to the community module; of these, approximately 30 percent were youth (under the age of $35)$.

Based on the number of youth included in responding to the community module in each of the 768 communities, the YEIC was developed, taking the values of $0=$ no youth involved, $1=$ only one youth participant, $2=$ two to three youth participants, and $3=$ more than four youth participants. Based on the index, the communities are as follows:

- Type 0 communities: NYP No youth engagement in community policy processes

- Type 1 communities: LYP Very low youth engagement

- Type 2 communities: MYP Average youth engagement

- Type 3 communities: GVY Good to very high youth engagement

The four different types of communities categorized by the YEIC were compared to one another using the factors extracted. 


\section{RESULTS AND DISCUSSIONS}

\section{Factors Determining Youth Engagement in Agricultural Policy Processes}

The analysis extracted 4 latent variables from the 24 observed variables that were included. The number of factors extracted and retained for interpretation was determined using a combination of scree plot analysis and the eigenvalues for each factor extracted. Scree plot analysis is the most common method in determining the number of factors for extraction (Tabachnick and Fidell 2000). Figure 5.1 presents the scree plot for this study. From the scree plot, it can be seen that from the 5 th factor there is a natural break point in the data with the graph flattening out until it reaches zero at the 24th factor. This implies that the first 4 factors account for the most variance in the factor loadings, while the remaining factors account for a very small amount of the variance. The eigenvalues for each factor extracted further confirm the extraction of 4 variables for interpretation (Appendix Table A.1) - as the first 4 variables have eigenvalues that are greater than 1.6 and account for more than half of the variance in the factor loadings (51 percent).

Figure 5.1 Scree plot of factors determining youth engagement in community policy processes

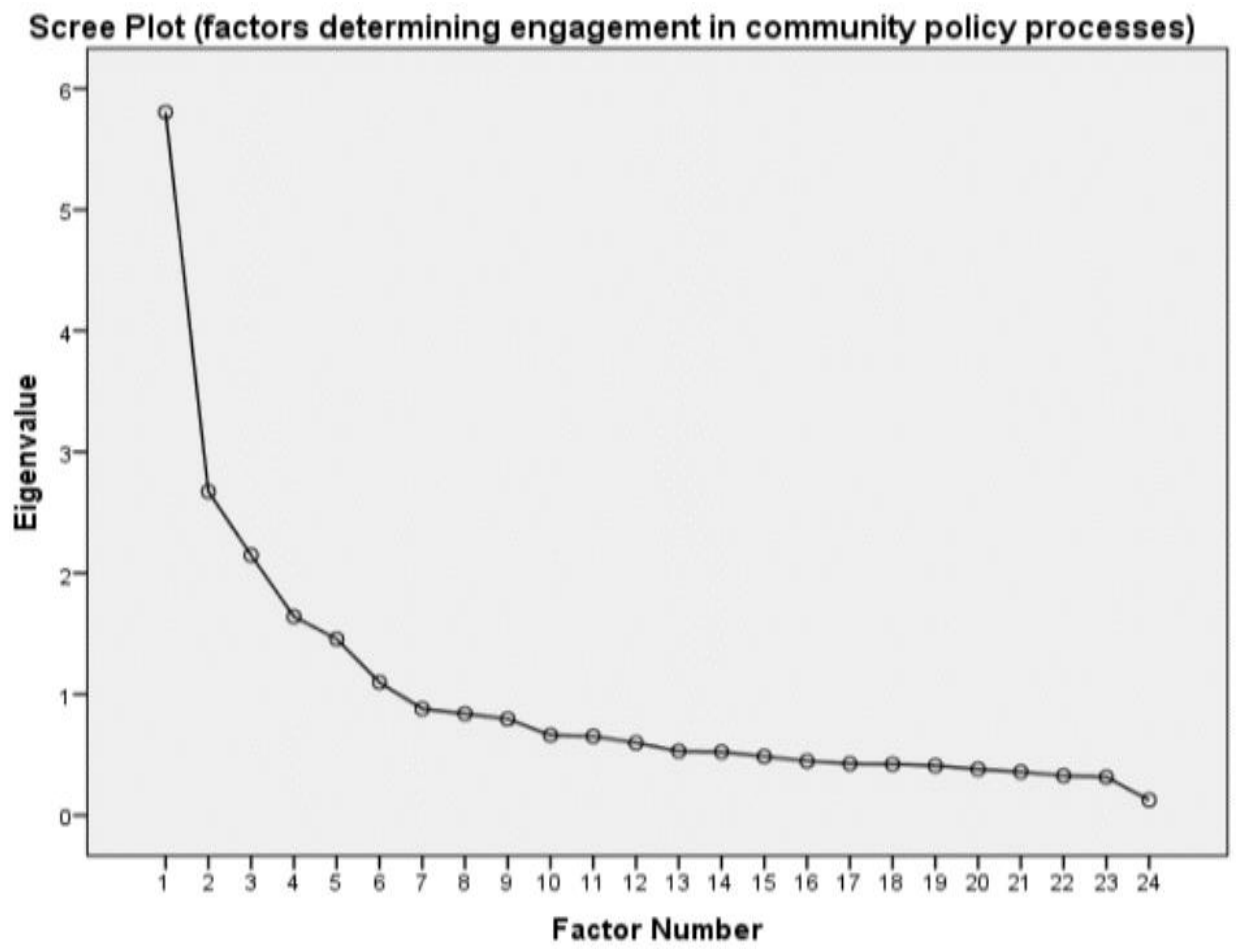

Source: Author's calculations using the 2010/2011 community module data of the 2010/2011 Integrated Household Survey (IHS-3).

From Table 5.1, the Kaiser-Meyer-Olkin (KMO) measure of sampling adequacy and Bartlett's test of sphericity show that the data used are highly suitable for factor analysis. This is because the KMO measure of sampling adequacy of 0.840 is far above the cutoff of 0.5. Second, the approximate chi square statistic for Bartlett's test of sphericity is $2,788.22$ and is highly statistically significant. The four underlying factors extracted were interpreted as (1) availability of social amenities and financial institutions, (2) capacity and information, (3) community accessibility, and (4) political patronage. Interpretation of an extracted factor used only observable variables that loaded on the particular factor with an eigenvalue of greater than 0.45 . These are presented in Table 5.1. 
Table 5.1 Results of principal factor analysis

\begin{tabular}{|c|c|c|c|c|}
\hline \multirow[b]{2}{*}{$\begin{array}{l}\text { Observable } \\
\text { variables }\end{array}$} & \multicolumn{4}{|c|}{ Factor Loadings ${ }^{2}$ (eigenvalues) } \\
\hline & $\begin{array}{l}\text { Factor } 1- \\
\text { Social } \\
\text { Amenities } \\
\text { Related }\end{array}$ & $\begin{array}{l}\text { Factor 2- } \\
\text { Capacity and } \\
\text { Information } \\
\text { Related }\end{array}$ & $\begin{array}{l}\text { Factor 3- } \\
\text { Accessibility } \\
\text { Related }\end{array}$ & $\begin{array}{c}\text { Factor } 4- \\
\text { Patronage } \\
\text { Related }\end{array}$ \\
\hline acc_road & & & 0.642 & \\
\hline acc_veh & & & 0.632 & \\
\hline acc_mbus & & & -0.638 & \\
\hline acc_lorry & & & -0.654 & \\
\hline acc_transp & & & 0.696 & \\
\hline dst_bus & 0.519 & & & \\
\hline loc_boma & & -0.615 & & \\
\hline MK_boma & 0.501 & & & \\
\hline Loc_urban & & -0.732 & & \\
\hline dst_mrk & 0.461 & & & \\
\hline dst_wmrk & 0.389 & & & \\
\hline dst_admarc & 0.439 & & & \\
\hline dst_post & 0.566 & & & \\
\hline dst_phone & 0.561 & & & \\
\hline edu_Pteach & & 0.747 & & \\
\hline Dst_sec & 0.606 & & & \\
\hline Edu_CDSS & & 0.480 & & \\
\hline edu_rsec & & 0.470 & & \\
\hline edu_pvtp & & 0.640 & & \\
\hline Edu_pvts & & 0.597 & & \\
\hline dst_cbank & 0.759 & & & \\
\hline dst_mfi & 0.771 & & & \\
\hline mp_resident & & & & 0.763 \\
\hline mp_visit & & & & 0.836 \\
\hline
\end{tabular}

Extraction method: principal axis factoring; rotation method: varimax with Kaiser normalization

Source: Author's computations using data from the community module of the 2010/2011 IHS-3.

Factor 1 has been renamed availability of social amenities and financial institutions because the 11 observed variables that loaded highly on this factor are all associated with the distance to social and financial services (Table 5.1). Proximity to social amenities and financial institutions does not necessarily enable the communities to engage in policy processes. However, this factor indicates that communities that are in greater proximity to social amenities and financial institutions are also closer to decisionmaking institutions. This is true in Malawi, with the majority of banks, credit organizations, and other social amenities being located at a district center (boma). The boma is also the administrative center for the local government. Social amenities therefore complement the desire of communities and individuals to participate in the development process, as they make it easier to do so. This factor therefore indicates that communities that are in closer proximity to social amenities have greater potential to participate in policy processes, as opposed to communities that are more isolated.

Factor 2 is renamed capacity and information, as all seven variables that have loaded highly on it are those that work toward building capacity as well as facilitating the availability and effective usage of

\footnotetext{
${ }^{2}$ Negative eigenvalues are not strange and often occur when using principal axis factoring.
} 
information. The variables related to educational institutions all work toward improving knowledge and capacity of community members as well as social preparedness to participate in community development. The location variables improve the availability of information, with communities in isolated rural areas plagued by information asymmetries due to their isolation and inadequate communication infrastructure. Therefore, communities in close proximity to a district center or urban areas are more likely to have access to information than those in remote areas. This finding complements the interpretation of Factor 1 above. The lack of information pertaining to one's rights, to community- and national-level programs, and to how to get involved in policy processes can hinder efforts to participate in the policy process or in community development activities. The education and location variables are complementary, as the ability to process available information and to use it effectively and to participate in community development activities is highly correlated with education (United Nations Development Fund 2010).

Five variables pertaining to the quality of the main road in the community and the availability of public transport services throughout the year loaded highly on Factor 3, renamed community accessibility. Good transport systems facilitate the movement of community members to centers of economic activity and services such as rural growth centers and district centers. For many rural communities in Africa, these economic hubs are often the nearest places for accessing information and other social services. Hence good transportation networks enable communities to access information, thus facilitating their involvement in any consultation processes in the agricultural sector that maybe taking place.

Two variables loaded highly on Factor 4, political patronage: the frequency with which the community's Member of Parliament (MP) has held meetings in the area in the last three months, and if the MP for the area lives in the community. Patronage may be beneficial for empowering communities or groups of individuals to participate in the development process. Political patronage is especially beneficial for the youth, as political obstacles also hinder the youth from effectively participating in policy processes (Bessant 2010). At the community level, the MP provides a formal space for community-level politics, especially as currently there are no other locally elected politicians. ${ }^{3}$ Therefore, this factor encompasses activities that are led by or channeled through the local MP and that may (or may not) work to enable a community and its individuals to overcome political obstacles that hinder them from fully participating in policy processes. For example, MPs galvanize communities to select youth to participate in national youth parliamentary forums. Participation in such forums as essential government policies and practices can be an obstacle to youth empowerment. Therefore understanding government and political processes is one of the key steps to empowering the youth.

These four factors are interlinked and interrelated. Significant positive correlations between some of the factors provide evidence of this (see Table A.2 in the Appendix for results of Spearman's rho test statistic). In addition, all the factors extracted can affect any member of the community (not just the youth) in their endeavors to engage in agricultural policy processes.

\section{Community-Level Differences Determining Youth Participation}

To determine how the different factors affect youth participation in community processes, the four types of communities categorized by the YEIC were compared with one another using the factors extracted. Factors scores themselves cannot be compared. However, different groups within the sample can be compared with each other by each factor extracted (using the factor scores and loadings). In this study, a two-way t-test with the assumption of unequal variances is used to compare each community with the others. Table 5.2 presents results of the students' t-test.

\footnotetext{
${ }^{3}$ Previously the country had locally elected councils. However, due to budgetary constraints, local council elections have not been held in the country since the 2000 democratic elections.
} 
Table 5.2 Pairwise comparison of communities by factors extracted

\begin{tabular}{|c|c|c|c|}
\hline Factor & $\begin{array}{l}\text { Community } \\
\text { Type }\end{array}$ & $\begin{array}{l}\text { Comparison } \\
\text { Community }\end{array}$ & $\mathbf{P}$ \\
\hline \multirow{6}{*}{$\begin{array}{l}\text { Factor 1: Social amenities and } \\
\text { financial institutions related }\end{array}$} & \multirow[t]{3}{*}{0} & 1 & 0.176 \\
\hline & & 2 & 0.352 \\
\hline & & 3 & 0.261 \\
\hline & \multirow[t]{2}{*}{1} & 2 & $0.081^{*}$ \\
\hline & & 3 & 0.997 \\
\hline & 2 & 3 & 0.140 \\
\hline \multirow{6}{*}{$\begin{array}{l}\text { Factor 2: Capacity and } \\
\text { information related }\end{array}$} & \multirow[t]{3}{*}{0} & 1 & 0.450 \\
\hline & & 2 & 0.250 \\
\hline & & 3 & 0.426 \\
\hline & \multirow[t]{2}{*}{1} & 2 & 0.512 \\
\hline & & 3 & 0.326 \\
\hline & 2 & 3 & 0.248 \\
\hline \multirow[t]{6}{*}{ Factor 3: Accessibility related } & \multirow[t]{3}{*}{0} & 1 & 0.643 \\
\hline & & 2 & 0.100 \\
\hline & & 3 & 0.166 \\
\hline & \multirow[t]{2}{*}{1} & 2 & 0.300 \\
\hline & & 3 & $0.013^{* *}$ \\
\hline & 2 & 3 & 0.917 \\
\hline \multirow{6}{*}{$\begin{array}{l}\text { Factor } 4 \text { : Political patronage } \\
\text { related }\end{array}$} & \multirow[t]{3}{*}{0} & 1 & 0.974 \\
\hline & & 2 & 0.652 \\
\hline & & 3 & 0.554 \\
\hline & \multirow[t]{2}{*}{1} & 2 & 0.384 \\
\hline & & 3 & 0.513 \\
\hline & 2 & 3 & 0.416 \\
\hline
\end{tabular}

Source: Author calculations

Notes: * Significant at $10 \%$ level, $* *$ significant at $5 \%$ level.

Table 5.2 shows weak statistically significant differences between communities with low youth participation and those with average youth participation in terms of Factor 1 (social amenities and financial institutions). In addition Table 5.2 also shows statistically significant differences between communities with low youth participation with those with good to very high youth participation in terms of Factor 3 (community accessibility). A few weak observations from these findings are that, first, lack of access to social amenities and financial institutions has a statistically significant negative impact on youth participation in community policy processes in which agriculture decisionmaking also takes place.

Second, remote rural communities are most likely to have little or no participation by the youth. This entails that policymakers make deliberate efforts to promote youth in agriculture to ensure that rural youth are empowered and enabled to participate in agricultural policy processes. This requires the mobilization of additional financial and technical resources to promote rural youth engagement in policy processes and development initiatives.

A point to note is that observations from results in Table 5.2 are weak due to the weakness of the statistically significant results and the lack of statistically significant differences between other community types. Therefore, further research is required in order to determine conclusively how differences between communities affect youth engagement in community policy process. 


\section{Perspectives on Factors Hindering Youth Engagement in Agricultural Policy Processes}

Key informant interviews with both youth and policymakers agree that youth are not effectively engaged in agricultural policy processes in Malawi. In addition, there is general agreement that policymakers do not make deliberate efforts to engage youth in agricultural policy process. This is due to the lack of a tangible policy or program for youth engagement within the agricultural sector. Key informant interviews with members of youth-led agriculture-focused organizations provided insight into the challenges facing young farmers. Youth organizations that were included in the analysis are those that are registered with and recognized by government and whose mandate (in way or another) focuses on working toward promoting the needs of the youth in agriculture (Table 5.4 has a list of all sampled organizations). The organizations sampled were those that represent young farmers in general at the national level, with some being those that are working at the district level. Many organizations had a mandate to work with both rural and urban youth.

Young farmers lack access to sufficient finance for investing in their farm enterprises. Two factors confound the youth further in their pursuits of agricultural based livelihoods. First is the rising costs of farm inputs, such as improved seeds and inorganic fertilizer, as well as high transaction costs associated with attempts to gain access to high-value markets. Second is land issues: Due to high population growth rates and continued cultivation, young farmers inherit land that is marginal in size and often highly degraded. This is the result of the traditional inheritance system of the country in which family land (under customary law) is subdivided and given to the younger generation as they come of age. Often the youth are given portions of land that are degraded due to overuse or marginal land that is not in use. Land that is more fertile is often under cultivation by elders, parents, older siblings, or a combination of these. Young farmers' perceptions are that the marginal land that they inherit requires high investments (such as investment in enhancing soil fertility) to yield good returns. Due to financial constraints, young farmers are unable to invest in improving the land they inherit from their parents.

Another key challenge, from the perspective of the youth, is that government support programs to the agricultural sector are insufficient. One particular example given was of the fertilizer subsidy program that provides coupons for subsidized inorganic fertilizer and hybrid maize and grain legume seed (such as seed for groundnuts and soya beans). Youth farmers felt that the program could have been more effective if it also included the provision of farm equipment and machinery. This would go far in reducing the drudgery associated with smallholder farming systems, thus improving efficiency. The youth that engaged in farming further stated that they lacked links to markets. This was due to either lack of information about lucrative markets or the lack of resources with which to produce sufficient quantities at the quality required by high-value markets. Many felt that government support programs should include an element of improving young farmer's linkages with markets. Such a support program should go hand in hand with the provision of subsidized inputs and equipment.

Concerning agricultural policy processes, the youth identified several problems that prevent them from effectively engaging in these processes.

- Lack of awareness of agricultural policy processes: Youth lack knowledge about agricultural policy processes. When the youth are aware of a policy debate, they lack the knowledge of how to get involved. Many attribute this problem to the failure of policymakers to inform the public about policy processes and to the lack of proactiveness on the part of the youth.

- Lack of appropriate support mechanisms: When the youth are aware that a policy process is taking place, they lack the ability to get themselves involved. This is attributed to a lack of government policy to deliberately engage youth at different levels of the policymaking process.

- Lack of government initiative to engage the youth: The perspective among the youth is that the government does not make an effort to engage the youth either through the sharing of information or facilitating youth participation. 
The following factors hinder effective engagement when the youth are involved:

- Capacity constraints: When youth engage with policymakers, they often lack the capacity to articulate their ideas effectively. In many cases, advocacy for the ideas of the youth fails due to the lack of proper presentation skills.

- Inadequate financial resources: Often policy process activities, such as consultation workshops and meetings, take place in central locations such as a city or district center (boma). Youth in isolated rural areas are unable to have their voice heard because they lack the financial resources to travel to and attend meetings.

- Youth attitudes: The youth perceive farming as an enterprise for people without alternatives. In addition, there is a general perception that farming is not a business but a way of life for those in the village. Many youth hope to exit the agricultural sector when they make sufficient money to invest in another type of business or when a different opportunity comes up.

- Culture of respect by silence: Youth stated that in general the Malawian cultural norms do not allow youth to express their opinions among elders. Therefore, policy dialogues reflect the culture of respect by silence.

On the other hand, key informant interviews with policymakers brought forth three points where all policymakers had a consensus:

- Youth are generally not engaged in policy processes. This is not only limited to the agricultural sector but is the case in many other sectors as well. The youth are usually involved only at the implementation stage of a policy, but rarely during the process.

- Policymakers are inappropriate people to represent the youth in policymaking processes. Inappropriate representation means that that the voice of the youth remains unheard and the dynamic and diverse views of the youth remain silent in policies.

- All the youth are willing to be involved in policy processes, but policymakers have not made deliberate efforts to engage the youth.

Many of the policymakers stated that agricultural policies are essentially silent about the youth or provide only minimal focus on them. A review of some policies and strategies of the Ministry of Agriculture and Food Security shows that this is not always the case. Table 5.3 shows that several agriculture policies and strategies of Malawi specifically mention the youth. Other policies and strategies do not explicitly refer to the youth, but they have general statements such as the following, which implicitly include the youth:

- All men, women and children

- All men, women, boys and girls

- All vulnerable members of society

- All farmers

- Child-headed households

- Households

- People

- Malawi's population 
Table 5.3 Major policies and strategies of the Malawi Ministry of Agriculture and Food Security: Youth-specific statements

\begin{tabular}{|c|c|c|}
\hline Policy or Strategy & Youth-specific statement/section & $\begin{array}{c}\text { Reference to } \\
\text { youth }\end{array}$ \\
\hline \multirow[t]{2}{*}{$\begin{array}{l}\text { Agricultural Sector Wide } \\
\text { Approach (ASWAp) } \\
\text { (September 2011) }\end{array}$} & $\begin{array}{l}\text { 3.4.4 ASWAp actions on gender, HIV, and AIDS: } \\
\text { The implementers of the ASWAp will therefore ensure that women } \\
\text { and the youth have access to technologies, information, financial } \\
\text { markets, participate in decisionmaking processes. }\end{array}$ & \multirow[t]{2}{*}{ Explicit } \\
\hline & $\begin{array}{l}\text { 4.1.6 Cross cutting issues-gender: } \\
\text { The ASWAp will respond to the needs of women farmers, youth and } \\
\text { people living with and affected by HIV by adopting a gender and HIV- } \\
\text { responsive targeting strategy... The ASWAp will also respond to the } \\
\text { needs of the youth, who will increasingly take on leadership roles in } \\
\text { the community. ASWAp will endeavor to ensure that the voices of the } \\
\text { youth are properly articulated into the development process. }\end{array}$ & \\
\hline $\begin{array}{l}\text { Food Security Policy } \\
\text { (August 2006) }\end{array}$ & $\begin{array}{l}\text { 2.2 Specific objective: } \\
\text { The specific objective of Food Security is to guarantee that all men, } \\
\text { women, boys and girls, especially under-fives in Malawi have, at all } \\
\text { times, physical and economic access to sufficient nutritious food } \\
\text { required to lead a healthy and active life. }\end{array}$ & Implicit \\
\hline $\begin{array}{l}\text { Farm Input Subsidy } \\
\text { Program (Medium Term } \\
\text { Plan for the FISP 3rd } \\
\text { Version, May 2011) }\end{array}$ & $\begin{array}{l}\text { 3.5.4 Beneficiary identification and targeting } \\
\text { FISP targets the resource poor smallholder maize farmers who own a } \\
\text { piece of land and are prepared to farm in the implementation year.... } \\
\text { resource poor households keeping the following dependents (people } \\
\text { with physical disabilities, elderly, chronically ill, orphans) will be given } \\
\text { priority. Poor resource female and child headed households will also } \\
\text { be given priority as well. }\end{array}$ & Implicit \\
\hline $\begin{array}{l}\text { New Extension Policy } \\
\text { (October 2000) }\end{array}$ & $\begin{array}{l}\text { 5.5 Equalization } \\
\text { While encouraging private sector involvement in extension service } \\
\text { delivery, the public sector must make sure that poorer segments of the } \\
\text { society, women, youth and people with disabilities are not left of the } \\
\text { development process for purposes of equity and equality. }\end{array}$ & Explicit \\
\hline $\begin{array}{l}\text { Greenbelt Initiative } \\
\text { Concept (January 2011) }\end{array}$ & $\begin{array}{l}\text { 1.3.2 Specific objectives: } \\
\text { \#5: Increase household incomes } \\
\text { \#10: Improve people's access to water for various uses } \\
\text { 2.1.5.3 Extension services: } \\
\text { The Program will support farmers of all gender categories with } \\
\text { integrated packages of extension services that address their needs. } \\
\text { This will involve supporting all stakeholders along various commodity } \\
\text { value chains by providing technical information from relevant } \\
\text { institutions through front line staff, lead and peer farmers. }\end{array}$ & Implicit \\
\hline
\end{tabular}

Source: Compiled by author based on desktop review of all included policies.

Policy documents that implicitly refer to the youth far outweigh those that explicitly refer to them. It is perhaps for this reason that the majority of policymakers sampled felt that policy documents are silent on the issue of the youth. It is possible, from the perspective of the policymakers that policies and strategies of the Ministry of Agriculture and Food Security that are silent on the youth emanate from their involvement in reviewing and evaluating the implementation of policies and strategies. Similarly, it is possible that the policies, both those that explicitly and those that implicitly refer to the youth, do not specially target the youth in their implementation. An assessment of how youth targeting takes place in policy implementation is outside the scope of this study - this is an as an area for future research. 


\section{Social Network Analysis}

To gain further insight into youth engagement in agricultural policy processes in the country, the study employed social network analysis, which measures and maps the nature of relationships between connected information entities, such as people, groups, and organizations (Knoke and Yang 2008; Scott 1987). This study employed social network analysis to assess the nature and extent of interactions between and among youth in agriculture, and with policymakers as well as nonstate actors. The technique provides both a visual and a mathematical assessment of relationships or connections in a network. Social network analysis achieves this by assessing the location of actors in a network. Measuring the network location or the centrality of an actor provides insight of who is at the center of a network, which actors are at the periphery, who is the lead, and who connects different groups of people. There are many measures of centrality: degree centrality (the number of direct network connections that an actor has), betweenness centrality (assessing which actors are between others, thus playing a role of information brokerage), and closeness centrality (how quickly an actor is able to have access to other actors in the network). The key measures of social network analysis that this study will analyze and some terminology are defined below.

Social networking measures analyzed in this study are below:

- Node: An individual actor, group, or organization within the network.

- Ego: A sampled node. An ego network is therefore the personal network of the sampled respondent (node).

- Size: The number of direct network connections that an individual node has. This shows the level of network activity.

- Ties: The number of direct ties between nodes. This shows the strength of connections between nodes in a network.

- Density: This is the proportion of ties (or relationships between actors), expressed as a percentage of all possible ties in that network. The denser the network, the higher the number of potential ties present. The network density gives insight about the speed at which information diffuses among network actors.

- Reach efficiency: How much secondary contact is gained through each unit of primary contact? If reach efficiency is high, then the actor is successful in reaching a wider audience through each of the actor's primary contacts.

- Betweenness centrality: Measured by broker and betweenness measures. Betweenness measures provide insight into actors that are brokers of information and have influence over what information flows (or does not flow) to others.

The social network analysis included interviews with different type of players within the agricultural sector in Malawi. These included policymakers that drive policy dialogue related to the agricultural sector and youth-led organizations working to advocate for the interests of (rural and urban) youth in agriculture. Government entities included the Ministry of Agriculture and Food Security; the Ministry of Youth, Sports, and Culture; the Ministry of Irrigation and Water Development; and Lilongwe District Youth Office. The social network analysis also included 10 youth-led organizations as well as the National Youth Council of Malawi (Table 5.4). Other organizations that were included in the social network analysis (specifically Tradeline Corporation and Community Finance) were identified by the sampled youth organizations as being key service providers and therefore were also included in the analysis. In social network analysis, it is standard practice to include all actors that are identified by the sampled respondents to fully map the network and its interactions. Table 5.4 provides the results of the social network analysis. 
Table 5.4 Ego network measures for the sampled agricultural youth network in Malawi

\begin{tabular}{|c|c|c|c|c|c|c|c|}
\hline Agency & Size & Ties & Pairs & Density & $\begin{array}{c}\text { Reach } \\
\text { efficiency }\end{array}$ & Broker & Betweenness \\
\hline \multicolumn{8}{|c|}{ Government ministries/departments } \\
\hline $\begin{array}{l}\text { Ministry of Youth, Sports, and } \\
\text { Culture }\end{array}$ & 12 & 44 & 132 & 33.33 & 17.24 & 44.00 & 17.50 \\
\hline $\begin{array}{l}\text { Ministry of Agriculture and } \\
\text { Food Security }\end{array}$ & 10 & 30 & 90 & 33.33 & 20.27 & 30.00 & 32.67 \\
\hline Ministry of Irrigation & 3 & 3 & 6 & 50.00 & 52.17 & 1.50 & 0.50 \\
\hline Lilongwe District Youth Office & 12 & 46 & 132 & 34.55 & 17.24 & 43.00 & 17.50 \\
\hline \multicolumn{8}{|l|}{ Youth organizations } \\
\hline $\begin{array}{l}\text { Farmers Forum for Trade and } \\
\text { Social Justice }\end{array}$ & 9 & 25 & 72 & 34.72 & 22.06 & 23.50 & 33.17 \\
\hline $\begin{array}{l}\text { Foundation for Irrigation and } \\
\text { Sustainable Development }\end{array}$ & 5 & 12 & 20 & 60.00 & 27.66 & 4.00 & 1.50 \\
\hline $\begin{array}{l}\text { Youth Empowerment and } \\
\text { Civic Education }\end{array}$ & 7 & 19 & 42 & 45.24 & 22.03 & 11.50 & 12.00 \\
\hline $\begin{array}{l}\text { Organization for Sustainable } \\
\text { Socio-Economic } \\
\text { Development Initiative }\end{array}$ & 3 & 4 & 6 & 66.67 & 38.24 & 1.00 & 0.00 \\
\hline Youth Watch Society & 5 & 10 & 20 & 50.00 & 27.91 & 5.00 & 0.00 \\
\hline $\begin{array}{l}\text { Network for Youth } \\
\text { Development }\end{array}$ & 6 & 18 & 30 & 60.00 & 25.86 & 6.00 & 5.00 \\
\hline $\begin{array}{l}\text { Lilongwe Youth Urban } \\
\text { Network }\end{array}$ & 6 & 18 & 30 & 60.00 & 25.86 & 6.00 & 9.17 \\
\hline $\begin{array}{l}\text { Center for Youth and Children } \\
\text { Affairs }\end{array}$ & 6 & 16 & 30 & 53.33 & 23.21 & 7.00 & 9.33 \\
\hline $\begin{array}{l}\text { Counseling of Adolescents } \\
\text { and Youth Organization }\end{array}$ & 8 & 27 & 56 & 48.21 & 21.74 & 14.50 & 4.42 \\
\hline \multicolumn{8}{|l|}{ Other organizations } \\
\hline $\begin{array}{l}\text { National Youth Council of } \\
\text { Malawi }\end{array}$ & 10 & 39 & 90 & 43.33 & 18.52 & 25.50 & 6.33 \\
\hline Trade Line Corporation & 2 & 2 & 2 & 100.00 & 81.82 & 0.00 & 0.00 \\
\hline Community Finance & 2 & 2 & 2 & 100.00 & 81.82 & 0.00 & 0.00 \\
\hline
\end{tabular}

Source: Author calculations generated from UCINET - a software package used for social network analysis.

Notes: $\quad$ Size $=$ size of ego network. Ties $=$ number of directed ties. Pairs $=$ number of ordered pairs. Density $=$ ties divided by pairs. Reach Efficiency $=2 *$ StepReach $\div$ Size. Broker $=$ Number of pairs not directly connected. Betweenness $=$ betweenness of ego in own network.

From Table 5.4 it can be seen that the Ministry of Youth, Sports, and Culture and the Lilongwe District Youth Office have the largest ego networks (size $=12$ ) of all the actors interviewed. This implies that among the sampled organizations, these two government departments interact directly with most of the sampled actors. The Ministry of Agriculture and the National Youth Council have the second largest ego network (size =10). As such, the Ministry of Youth, Sports, and Culture and the Lilongwe District Youth Office are possibly more important hubs of information and knowledge among agriculture youth organizations in the country than the Ministry of Agriculture and Food Security or the Youth Council. Differences in the number of direct interactions with the youth-led organizations between the Ministry of Youth, Sports, and Culture and the District Youth Office with the Ministry of Agriculture and Food Security are attributed to the fact that the first two government departments have a core mandate to deal 
with the youth. The core mandate of the Ministry of Agriculture and Food Security is broad in that it is agricultural development of the country, and the Ministry of Agriculture and Food Security has a broad spectrum of actors, which include the youth.

An assessment of the number of connections (ties) among all the actors in the network of each of the four organizations having the largest ego networks reveals several key issues. First, organizations with the same network size do not necessarily have the same number of ties. This is the case for both the nodes with the largest and the second largest network size. For example the District Youth Office has a larger number of directed ties (ties $=46$ ) than the Ministry of Youth, Sports, and Culture (ties $=44$ ), despite that both organizations have the same network size. We also observe that the National Youth Council has a larger number of ties among the nodes in its ego network (ties $=39$ ) than the Ministry of Agriculture (ties $=30$ ), again despite the same network size. The implications are that key informants perceive the District Youth Office to have stronger ties with their primary contacts than the Ministry of Youth, Sports, and Culture. This is the same for the National Youth Council in that there is a perception that it has stronger ties to its primary connections than the Ministry of Agriculture and Food Security has. From all the organizations sampled, the District Youth Office has more numerous ties with their primary connections - this is the general perception of sampled organizations. In addition, the District Youth Office and the Ministry of Youth, Sports, and Culture have very high broker measures compared with others in the network. This confirms their important role in facilitating the exchange of information and knowledge with the youth in agriculture in the country.

The two ministries sampled have relatively weaker perceived ties when compared to the districtlevel youth office and the National Youth Council, which both had similarly sized networks. Key informant (both youth and policymaker) perceptions are that bureaucracy and hierarchical systems limit youth interactions with the government. National-level government systems create bottlenecks that hinder access by youth to information, other resources, and in some cases personnel. Many youth representatives also perceive government as being secretive - in contrast to nongovernmental organizations. From the ego measures, this perception does not include the Lilongwe District Youth Office, which is also a public entity. This can be attributed to a high frequency of interactions between the district youth office, but more importantly to the perception of the ease of interaction. District youth offices in Malawi are part of the Ministry of Local Government housed at the District Commissioners Offices, where many other social services are offered and to which all actors are freely able to walk in. The District Commissioners Office also acts as the main entry point for all stakeholders working within a district. Discussions with the youth and ministry officials show that the type of interaction between youth and government is mainly information sharing by government and consultation with the youth. There are little or no established partnerships as described in Figure 5.2. 
Figure 5.2 Social network analysis: Malawi youth agriculture network

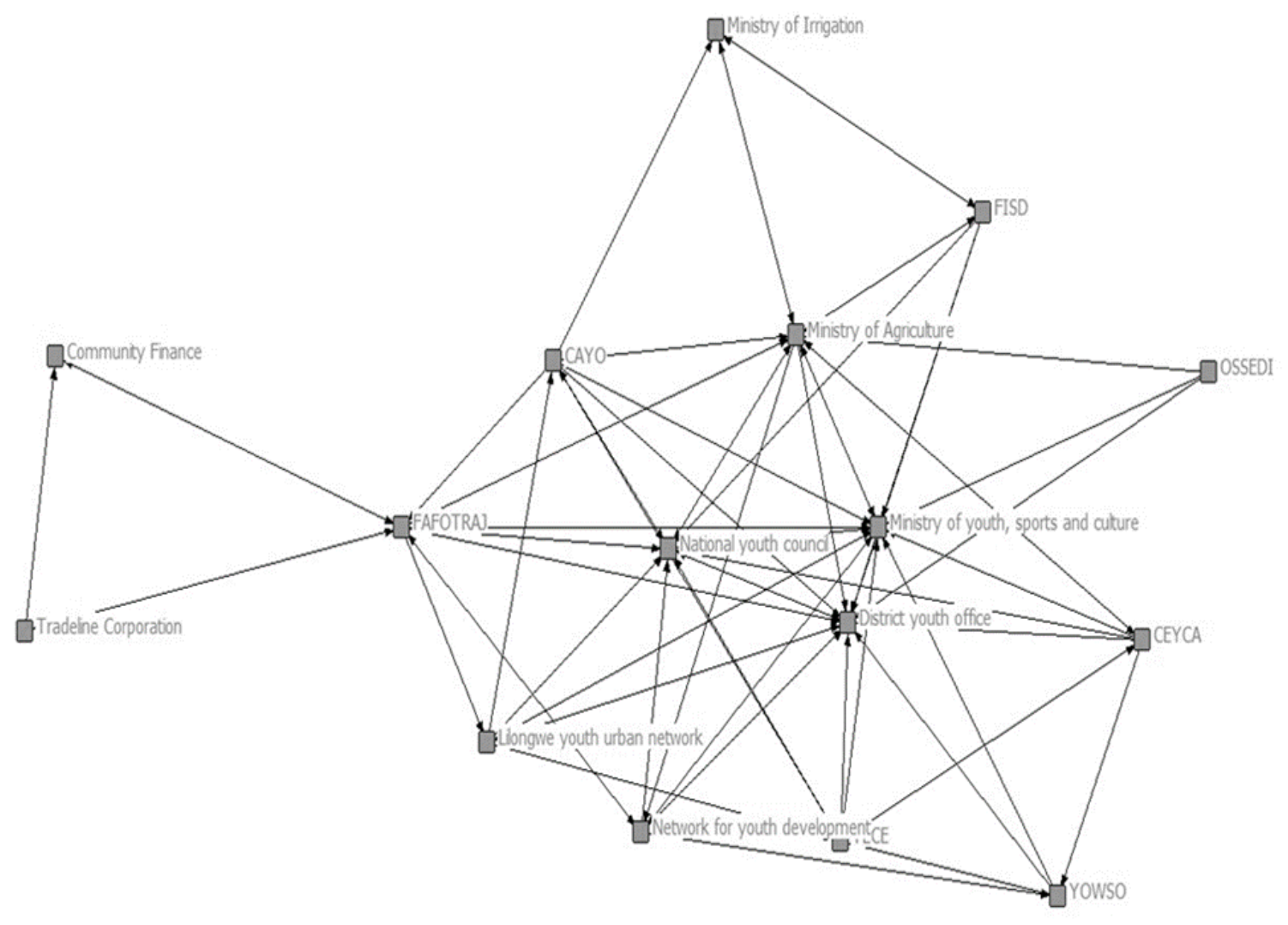

Source: Author calculations.

Any efforts to engage the youth must utilize existing government systems and structures at the local level that already act as hubs for social services and information. To a lesser extent, policymakers stated that other factors restricting networking with the youth are mistrust of their motives for seeking information, as well as general disregard for youth opinions. The Ministry of Agriculture and Food Security, however, remains essential for any efforts to improve the engagement of the youth in policy processes and to link the youth with other actors outside their own immediate networks. As Table 5.4 further shows, among the larger actors the Ministry of Agriculture and Food Security has relatively high reach efficiency and the highest betweenness measures. This implies that the ministry has a high reach beyond its primary points of contacts, with secondary contacts in their network also being important. In addition, this implies that the ministry can have great influence over the information that flows to different stakeholders - hence, it is an important link between youth in agriculture and other actors, such as development partners.

From Figure 5.2 and from the ego network measures in Table 5.4, we observe that there are very few direct connections between youth organizations. Many of the indirect connections are weak, with the distance between the youth organizations being very long. Due to the lack of direct connections between the youth, there is the lack of knowledge of other youth in agriculture and their initiatives. In cases in which the youth are knowledgeable of each other, they have insufficient financial resources to organize themselves. Mistrust and secretiveness are the key factors perceived as restricting youth-to-youth networking. In many instances, youth organizations are competing for scarce resources from a limited pool of public and private funds. These factors combined prevent the youth from working effectively as a collective to form a consolidated platform, if they had wanted to do so. Among the youth organizations, 
we observe that the Farmers Forum for Trade and Social Justice (FAFOTRAJ) has a relatively large number of ties, higher broker measures, and high betweenness measures. This implies that among the youth organizations sampled, FAFOTRAJ has good connectivity and as such can act as a broker of information and knowledge. Thus, it provides a linkage between other youth organizations and other actors that do not have primary connections.

To overcome the factors limiting effective networking with policymakers and among the youth, key informants suggested different solutions. A summary is in Table 5.5.

Table 5.5 Key informant solutions to overcoming networking hurdles for youth in agriculture

\begin{tabular}{|c|c|}
\hline Demand side (youth) & Supply side (policymakers) \\
\hline \multirow[t]{2}{*}{$\begin{array}{l}\text { Improved networking among the youth for improved } \\
\text { information sharing. This would create familiarity and } \\
\text { thus be a step to remove the mentality that youth } \\
\text { organizations are in competition (for scarce resources } \\
\text { and recognition). }\end{array}$} & $\begin{array}{l}\text { Need for a deliberate agricultural sector policy to } \\
\text { engage the youth in policy processes. To ensure } \\
\text { that such a policy is enacted, the ministry should } \\
\text { establish a section under the directorate of the } \\
\text { Agricultural Extension Services that focuses on the } \\
\text { youth. }\end{array}$ \\
\hline & $\begin{array}{l}\text { Need to improve access to information such as } \\
\text { ministry reports and other documents pertaining to } \\
\text { agricultural policies. }\end{array}$ \\
\hline \multirow[t]{2}{*}{$\begin{array}{l}\text { Need for deliberate effort by government to involve the } \\
\text { youth. This should be facilitated by organizations such } \\
\text { as the National Youth Council that are mandated to } \\
\text { promote empowerment of the youth but also that have } \\
\text { convening power as well the human and financial } \\
\text { resources with which to mobilize the youth. }\end{array}$} & $\begin{array}{l}\text { Policymakers need to have greater interaction with } \\
\text { the youth as a separate constituency from other } \\
\text { stakeholders in the sector. This can be done } \\
\text { through informal dialogue sessions at different } \\
\text { levels, such as national or local government through } \\
\text { the district commissioners or district youth officers. }\end{array}$ \\
\hline & $\begin{array}{l}\text { Conduct awareness campaigns for the general } \\
\text { population of agricultural policy issues. This will } \\
\text { solicit public interest to provide input during the } \\
\text { policy process. }\end{array}$ \\
\hline
\end{tabular}

Source: Author summaries from key informant interviews.

The consensus between policymakers and youth advocates is that a need exists for deliberate and more effective engagement of the youth by policymakers in agricultural policymaking processes. The youth advocates call for improved networking among youth-led organizations, which would create opportunities for information sharing. In addition, the youth advocates also call for deliberate efforts by the public sector to involve and engage the youth in the agricultural policy dialogue. Many views of policymakers mirror the views of the youth advocates. Policymakers support the idea of the deliberate engagement of the youth in agricultural policy dialogue, and the need for the public sector to make information sharing with the youth easier. They also advocate for greater interaction between policymakers and the youth as a separate constituency from other stakeholders within the sector. Finally, policymakers also stated that as part of increasing awareness of agricultural policy dialogues, there is need for public awareness campaigns. These campaigns would be used to provide the public with information about current and forthcoming policy issues as well as an opportunity for the public (including the youth) to provide input. 


\section{CONCLUSIONS AND POLICY RECOMMENDATIONS}

Using a mixed-methods approach, we analyze the barriers and enabling factors that determine youth engagement in agricultural policy processes in Malawi from both the supply and demand side. We also assess the nature of interactions and networking between youth and agricultural policymakers in southern Africa using Malawi as a case study. The findings show that, first, four interlinked latent factors determine youth engagement in agricultural policy processes: political patronage, social amenities, access to information and educational services, and physical accessibility; second, exclusion of youth in remote rural communities from agricultural policy dialogue is more prevalent; and third, public departments mandated to work on youth-related issues are the main hubs of information and knowledge for youth in agriculture, with the local government youth offices acting as the main hub for information for youth in agriculture.

Furthermore, the study finds that youth in agriculture have weak or no direct interactions with each other. As a result of this, as well as other factors such as the lack of active engagement efforts by government, the youth remain on the periphery of the agricultural policymaking network, and their role in shaping policy dialogue is negligible. Therefore, the need exists for government, in consultation with all relevant stakeholders including the youth, to develop a policy that ensures the deliberate engagement of the youth in all agricultural-sector policies and programs. Such a policy, however, can be effective only if the youth are empowered to engage with policymakers and with the issues at hand. This therefore requires that government in partnership with the private sector invest in building the capacity of the youth, either as individuals or as youth organizations, to engage with policymakers. Any capacity-building efforts should encompass the diverse range of the youth in Malawi-both rural and urban youth, youth that are already pursing agriculture as a livelihood, smallholder subsistence farmers, and those that are idle and unemployed. A key focus of capacity-building programs should be on improving the understanding of young farmers of pertinent agricultural policy issues, of policy processes, and of the role that the youth can play in shaping policy dialogue. Such programs should also work to improve the articulation and communication skills of youth to enable them to engage effectively with policymakers. In addition, the government should establish a unit in the Ministry of Agriculture and Food Security that specifically deals with the issues pertaining to youth in agriculture and farming. This would go far to ensure that youth are collaborated in the policy development and implementation processes. Any efforts to engage the youth must use existing government systems and structures at the local government that are already acting as hubs for social services and information. Any public or private initiatives must specifically target youth in remote rural areas. From the findings of this study, it would be prudent to assess the feasibility of using existing district youth offices within the Ministry of Local Government as "agriculture youth units."

Finally, this study concludes that the onus is on the youth. To ensure that the youth in southern Africa are engaged on a sustained and effective basis with agricultural policymakers, there is need for a concerted effort by the youth in farming and agriculture to create a vibrant platform for engaging with policymakers. This is imperative for empowering rural youth. Currently many youth-led organizations are working to promote youth in farming and agriculture. However, they do not have a common and vibrant platform for lobbying and advocacy. By creating a joint platform, the youth can consolidate their ideas and combine financial and technical resources to create a powerful movement for lobbying and advocating agricultural policymakers. This will ensure effective engagement of the youth in the development of these policies.

Further research is essential to enable the youth to engage effectively with policymakers. Key focus areas for future research include assessing the viability of alternative approaches to youth engagement in the agricultural policy process and analyzing the disparities between rural and urban youth to ensure inclusiveness in the engagement process. Another key research area is to determine how effectively local government structures and systems and traditional systems can be effectively utilized to improve the engagement of the youth in agricultural policy processes. Comparative studies of different countries in the southern African region would go far to enhance knowledge and to facilitate change. 


\section{APPENDIX: SUPPLEMENTARY TABLES}

Table A.1 Principal axis factor analysis: Total variance explained

\begin{tabular}{|c|c|c|c|c|c|c|c|c|c|}
\hline \multirow[b]{2}{*}{ Factor } & \multicolumn{3}{|c|}{ Initial Eigenvalues } & \multicolumn{3}{|c|}{$\begin{array}{l}\text { Extraction Sums of } \\
\text { Squared Loadings }\end{array}$} & \multicolumn{3}{|c|}{$\begin{array}{l}\text { Rotation Sums of } \\
\text { Squared Loadings }\end{array}$} \\
\hline & Total & $\begin{array}{c}\% \text { of } \\
\text { Variance }\end{array}$ & $\begin{array}{l}\text { Cumul- } \\
\text { ative \% }\end{array}$ & Total & $\begin{array}{c}\% \text { of } \\
\text { Variance }\end{array}$ & $\begin{array}{l}\text { Cumul- } \\
\text { ative \% }\end{array}$ & Total & $\begin{array}{c}\% \text { of } \\
\text { Variance }\end{array}$ & $\begin{array}{l}\text { Cumul- } \\
\text { ative } \%\end{array}$ \\
\hline 1 & 5.806 & 24.190 & 24.190 & 5.259 & 21.913 & 21.913 & 3.527 & 14.695 & 14.695 \\
\hline 2 & 2.673 & 11.138 & 35.329 & 2.103 & 8.762 & 30.675 & 3.075 & 12.810 & 27.506 \\
\hline 3 & 2.148 & 8.948 & 44.277 & 1.610 & 6.710 & 37.385 & 2.313 & 9.638 & 37.143 \\
\hline 4 & 1.641 & 6.837 & 51.114 & 1.276 & 5.317 & 42.702 & 1.334 & 5.558 & 42.702 \\
\hline 5 & 1.456 & 6.066 & 57.179 & & & & & & \\
\hline 6 & 1.098 & 4.573 & 61.752 & & & & & & \\
\hline 7 & 0.880 & 3.667 & 65.420 & & & & & & \\
\hline 8 & 0.839 & 3.497 & 68.917 & & & & & & \\
\hline 9 & 0.796 & 3.315 & 72.232 & & & & & & \\
\hline 10 & 0.661 & 2.756 & 74.987 & & & & & & \\
\hline 11 & 0.653 & 2.721 & 77.709 & & & & & & \\
\hline 12 & 0.598 & 2.492 & 80.201 & & & & & & \\
\hline 13 & 0.530 & 2.208 & 82.408 & & & & & & \\
\hline 14 & 0.524 & 2.183 & 84.592 & & & & & & \\
\hline 15 & 0.486 & 2.024 & 86.615 & & & & & & \\
\hline 16 & 0.447 & 1.863 & 88.478 & & & & & & \\
\hline 17 & 0.426 & 1.775 & 90.253 & & & & & & \\
\hline 18 & 0.422 & 1.758 & 92.011 & & & & & & \\
\hline 19 & 0.409 & 1.706 & 93.717 & & & & & & \\
\hline 20 & 0.381 & 1.586 & 95.303 & & & & & & \\
\hline 21 & 0.359 & 1.496 & 96.799 & & & & & & \\
\hline 22 & 0.327 & 1.362 & 98.161 & & & & & & \\
\hline 23 & 0.315 & 1.314 & 99.475 & & & & & & \\
\hline 24 & 0.126 & 0.525 & 100.000 & & & & & & \\
\hline
\end{tabular}

Source: Author's calculations based on IHS-3 data (community module).

Note: Extraction method: principal axis factoring.

Table A.2 Spearman's rho results: Correlations between extracted factors

\begin{tabular}{lcccc}
\hline Factor & Factor 1 & Factor 2 & Factor 3 & Factor 4 \\
\hline Factor 1-Social Amenities & 1 & & & \\
Factor 2-Capacity and information & 0.29 & 1 & & \\
Factor 3-Accessibility related & -0.063 & $0.121^{\star *}$ & 1 & \\
Factor 4-Political patronage & $-0.086^{*}$ & $0.171^{* *}$ & -0.017 & 1 \\
\hline
\end{tabular}

Source: Author estimations.

Notes: *Correlation is significant at the 0.05 level; ** Correlation is significant at the 0.01 level. 


\section{REFERENCES}

Anyidoho, N. A., H. Kayuni, J. Ndungu, J. Leav y, M. Sall, G. Tadele and J. Sumberg. 2012. Young People and Policy Narratives in Sub-Saharan Africa. FAC Working Paper 032. Brighton, UK: The Future Agricultures Consortium.

Bennell, P. 2007. "Promoting Livelihood Opportunities for Rural Youth.” International Fund for Agricultural Development (IFAD). Accessed September 14. www.ifad.org/events/gc/30/ roundtable/youth/benell.pdf.

Bessant, J. 2010. "Mixed Messages: Youth Participation and Democratic Practice." Australian Journal of Political Science 39 (2): 387-404.

CASE (Community Agency for Social Enquiry). n.d. "The Situation of Youth in the Southern Africa Development Community: An Overview of SADC Countries - Case Summaries." Accessed June 29. www.ydn.org.za/publications/yes/finalexecreport.htm\#_Toc53811231.

Chinsinga, B., and M. Chasukwa. 2012. Youth, Agriculture and Land Grabs in Malawi. Paper prepared for the conference Young People, Farming, and Food. March 19-21. Accra, Ghana. Accessed June 15. www.future-agricultures.org/.../1504-youth-agriculture-and-land-grabs-in-malawi.

Costello, A. B., and J. Osborne. 2005. "Best Practices in Exploratory Factor Analysis: Four Recommendations for Getting the Most from Your Analysis." Practical Assessment Research and Evaluation 10 (7): 131-146. Accessed April 7. http://pareonline.net/getvn.asp?v=10\&n=7.

Curtain, R. 2001. 'Youth and Employment: a Public Policy Perspective', Development Bulletin 55(August 2001): 7-11.

DFID (Department for International Development). 2010. Youth Participation in Development: A Guide for Development Agencies and Policymakers. London: DFID- Civil Society Organisations Youth Working Group.

Dubois, O., and U. G. Ciamarra. 2009. "Making Sense of Policy Processes." Accessed July 4. www.fao.org/docs/up/easypol/541/making-sense_policy_processes_169en.pdf.

Euromonitor. 2012. "Special Report: The World's Youngest Populations." Euromonitor. London. Accessed September 8. http://blog.euromonitor.com/2012/02/special-report-the-worlds-youngestpopulations-.html.

IFAD (International Fund for Agricultural Development). 2011. "Feed Future Generations: Young Rural People Today-Prosperous, Productive Farmers Tomorrow.” Accessed September 14. www.ifad.org/events/gc/34/panels/proceedings.pdf.

Hayes, W. 2009. "Defining Public Policy: The Public Policy Cycle.” Accessed September 17. http://profwork.org/pp/study/define.html.

Knoke, D., and S. Yang. 2008. Social Network Analysis. Sage Publications: Los Angeles.

Leavy, J., and S. Smith. 2010. Future Farmers? Exploring Youth Aspirations for African Agriculture. Futures Agricultures Consortium Policy Brief 037. Accessed June 14. www.futureagricultures.org.

Malawi, MYSC (Ministry of Youth, Sports, and Culture). n.d. "Malawi National Youth Policy." Accessed June 29. www.nycommw.org/docs/youth_policy.pdf.

MOAFS (Ministry of Agriculture and Food Security). 2011. Malawi Agriculture Sector Wide Approach: A Prioritized and Harmonized Development Agenda: 2011-2015. Lilongwe.

OECD (Organization for Economic Development). 2001. "Citizens as Partners: Information, Consultation and Public Participation in Policymaking." Paris: OECD. Accessed July 3. www.ecnl.org/dindocuments/214_OECD_Engaging\%20Citizens\%20in\%20Policy-Making.pdf. 
Okali, C., and J. Sumberg. 2012. Quick Money and Power: Tomatoes and Livelihood Building in Rural Brong Ahafo, Ghana. Paper prepared for the conference Youth, People, Farming, and Food. March 19-21. Accra, Ghana. Accessed September 12. www.future-agricultures.org/component/ docman/cat_view/1569-young-people-farming-and-food-conference/1570-conferencepapers?start=10.

Population Reference Bureau. 2011. "World Population Data Sheet." Population Reference Bureau. Washington, DC: United States Agency for International Development. Accessed March 29. www.prb.org/pdf11/2011population-data-sheet_eng.pdf.

Proctor, F., and V. Lucchesi. 2012. Small-Scale Farming and Youth in an Era of Rapid Rural Change. London/The Hague: International Institute for Environment and Development/ International Humanist Institute for Cooperation with Developing Countries. Accessed June 14. pubs.iied.org/pdfs/14617IIED.pdf.

Sandford, S. 1985. Better Livestock Policy for Africa. African Livestock Policy Analysis Network (ALPAN) paper 1. Addis Ababa, Ethiopia: International Livestock Centre for Africa. Accessed September 17. www.fao.org/wairdocs/ILRI/x5499E/x5499e00.htm\#Contents.

Scott, J. 1987. Social Network Analysis: A Handbook. London: Sage Publications.

Sumberg, J. 2012. "Conference Background." Overview of the conference Young People, Farming, and Food. March 19-21. Accra, Ghana. Accessed September 14. www.future-agricultures.org/ conference-background.

Tabachnick, B. G., and L. S. Fidell. 2000. Using Multivariate Statistics. 4th Edition. New York: HarperCollins.

te Lintelo, D. J. H. 2012. Unspoken Assumptions: Youth Participation and the African Policy Process. Paper prepared for the conference Youth, People, Farming and Food. March 19-21. Accra, Ghana. Accessed September 14. http://dialogue2012.fanrpan.org/sites/default/files/publications/ te Lintelo_Unspoken assumptions revised.pdf.

United Nations Development Fund. 2010. "Swiss-UNDP (S-UN) Fund for Youth Recommendations for Youth Participation and Policies." Accessed July 6. www.undp.org.tr/publicationsDocuments/ Recommendations_on_Youth_Participation_and_Policies.pdf.

White, B. 2012. "Agriculture and the Generation Problem: Rural Youth, Employment and the Future of Farming." Paper prepared for the conference Youth, People, Farming and Food. March 19-21. Accra, Ghana. Accessed September 14. www.future-agricultures.org/component/ docman/cat_view/1569-young-people-farming-and-food-conference/1570-conference-papers. 


\section{RECENT IFPRI DISCUSSION PAPERS}

\section{For earlier discussion papers, please go to www.ifpri.org/pubs/pubs.htm\#dp. All discussion papers can be downloaded free of charge.}

1334. Can cash transfers promote the local economy?: A case study for Cambodia. Stephanie Levy and Sherman Robinson, 2014.

1333. Gender, control, and crop choice in northern Mozambique. Alan de Brauw, 2014.

1332. Employment risk and job-seeker performance. Susan Godlonton, 2014.

1331. Food prices and poverty reduction in the long run. Derek Headey, 2014.

1330. Impact of Ghana's Agricultural Mechanization Services Center Program. Samuel Benin, 2014.

1329. Aid effectiveness: How is the L'Aquila Food Security Initiative doing? Samuel Benin, 2014.

1328. Improved dairy cows in Uganda: Pathways to poverty alleviation and improved child nutrition. Nassul Kabunga, 2014.

1327. A comparative analysis of global cropping systems models and maps. Weston Anderson, Liangzhi You, Stanley Wood, Ulrike Wood-Sichra, and Wenbin Wu, 2014.

1326. Population pressure and livelihood dynamics: Panel evidence from Bangladesh. Shahidur Rashid, Nigussie Tefera, Solomon Lemma, and Mohammed Yunus, 2014.

1325. Changing sources of growth in Indian Agriculture: Implications for regional priorities for accelerating agricultural growth. Pratap S. Birthal, Pramod K. Joshi, Digvijay S. Negi, and Shaily Agarwal, 2014.

1324. Risk and Ambiguity Preferences and the Adoption of New Agricultural Technologies: Evidence from Field Experiments in Rural India. Patrick S. Ward and Vartika Singh, 2014.

1323. Land, Assets, and Livelihoods: Gendered Analysis of Evidence from Odisha State in India. Vivien Savath, Diana Fletschner, Amber Peterman, and Florence Santos, 2014.

1322. Exploring local perceptions of climate change impact and adaptation in rural Bangladesh. Peter Davis and Snigdha Ali, 2014.

1321. Closing the gender asset gap: Learning from value chain development in Africa and Asia. Agnes R. Quisumbing, Deborah Rubin, Cristina Manfre, Elizabeth Waithanji, Mara van den Bold, Deanna Olney, and Ruth Meinzen-Dick, 2014.

1320. The political economy of Zambia's recovery: Structural change without transformation? Danielle Resnick and James Thurlow, 2014.

1319. The impact of Bolsa Familia on schooling: Girls' advantage increases and older children gain. Alan de Brauw, Daniel O. Gilligan, John Hoddinott, and Shalini Roy, 2014.

1318. Exploring strategic priorities for regional agricultural research and development investments in Southern Africa. Michael Johnson, Samuel Benin, Liangzhi You, Xinshen Diao, Pius Chilonda, and Adam Kennedy, 2014.

1317. How do intrahousehold dynamics change when assets are transferred to women?: Evidence from BRAC's Challenging the Frontiers of Poverty Reduction-Targeting the Ultra Poor Program in Bangladesh. Narayan Das, Rabeya Yasmin, Jinnat Ara, Md. Kamruzzaman, Peter Davis, Julia A. Behrman, Shalini Roy, and Agnes R. Quisumbing, 2013.

1316. Is there an app for that?: The impact of community knowledge workers in Uganda. Bjorn Van Campenhout, 2013.

1315. Can integrated agriculture-nutrition programs change gender norms on land and asset ownership: Evidence from Burkina Faso. Mara van den Bold, Abdoulaye Pedehombga, Marcellin Ouedraogo, Agnes R. Quisumbing, and Deanna Olney, 2013.

1314. Moving in the right direction?:Maize productivity and fertilizer use and use intensity in Ghana. Antony Chapoto and Catherine Ragasa, 2013.

1313. Women's empowerment in agriculture, production diversity, and nutrition: Evidence from Nepal. Hazel Jean L. Malapit, Suneetha Kadiyala, Agnes R. Quisumbing, Kenda Cunningham, and Parul Tyagi, 2013.

1312. Don't tell on me: Experimental evidence of asymmetric information in transnational households. Kate Ambler, 2013. 


\section{INTERNATIONAL FOOD POLICY RESEARCH INSTITUTE}

www.ifpri.org

IFPRI HEADQUARTERS

$2033 \mathrm{~K}$ Street, NW

Washington, DC 20006-1002 USA

Tel.: +1-202-862-5600

Fax: +1-202-467-4439

Email: ifpri@cgiar.org

IFPRI LILONGWE

PO Box 31666

Lilongwe 3

Malawi

Tel.: +265-1-789747

Email: IFPRI-Lilongwe@cgiar.org 